\title{
Effects of the Forest Healing Program on Depression, Cognition, and the Autonomic Nervous System in the Elderly with Cognitive Decline
}

\author{
Young-suwn Lim ${ }^{1}$, Jaeuk Kim²*, Taegyu Khil ${ }^{1}$, Jiyune $\mathrm{Yi}^{1}$, and Dong-jun Kim ${ }^{3}$ \\ ${ }^{1}$ Researcher, Department of Forest Therapy, Graduate School, Chungbuk National University, Cheongju 28644, Korea \\ ${ }^{2}$ Chief researcher, Korea Institute of Oriental Medicine, Daejeon 34054, Korea \\ ${ }^{3}$ Professor, Department of Forestry Chungbuk National University, Cheongju 28644, Korea
}

\section{ABSTRACT}

Background and objective: The purpose of this study is to investigate the effect of a forest healing program in terms of depression, neuropsychological and physiological benefits for the elderly.

Methods: For this purpose, we developed a forest therapy program for the elderly who are vulnerable to dementia and conducted a total of 11 sessions of forest therapy activities in a forest once a week. We measured the changes in depression, resting-state Electroencephalography(EEG) and heart rate variability (HRV) before and after the program. There were 60 subjects aged over 65 yesrs old. 30 subjects participated in the forest therapy program, and the other were in the control group. The Geriatric Depression Scale was used to measure the level of depression, neuroNicle FX2 (Laxtha, Korea) was used to measure the resting-state EEG, and photoplethymogram (ubpulse T1, Laxtha, Korea) was used to measure the HRV.

Results: The results showed that the depression index of the experimental group improved with statistical significance after the program (experiment group $=3.267$ decrease of the mean). In the EEG measurement, the alpha-peak frequency at rest (experimental group $=0.227 \mathrm{~Hz}$ increase of the mean) was improved (mean increase $=0.23$ in the experimental group, $p<.05$ ). The high frequency of HRV, which represents the parasympathetic nerve activity of the body's autonomous response, was also significantly improved (mean increase $=0.396$ in the experimental group, $p<.05$ ).

Conclusion: The results suggest that the forest therapy program can reduce the cognitive, psychological and physical risk factors of dementia for the elderly at risk of cognitive decline. Therefore, forest therapy activities may be suitable for the prevention of dementia in the elderly.

Keywords: alpha-peak frequency, cognitive improvement, neuropsychological assessment, urban forest

\section{Introduction}

Recently, with a growing interest in the value and therapeutic effects of forests as a resource for health promotion, the government and the private sector are paying attention to and making efforts in the use of the therapeutic function of forests as a solution to the aging society. The elderly population aged 65 and over in South Korea accounted for $3.1 \%$ of the entire population in the $1970 \mathrm{~s}$, but due to the extension of the average lifespan and decrease in birth rates, the percentage increased to $5.1 \%$ in 1990 and $14.8 \%$ in 2018, and it is expected to surpass $30 \%$ in 2030 (Korea Statistical Information Service, 2018). Korea is rapidly entering the aged society unlike advanced countries that have been coping with population aging throughout a long period of time, and this rapid increase of the elderly population and extension of the average lifespan indicate prolonged senescence.

\footnotetext{
This research was supported by the Korea Forestry Promotion Institute (grant no. 2018124A00-1920-AB01) funded by the Korea Forest Service. Received: November 5, 2019, Revised: December 2, 2019, Accepted: December 10, 2020

First author: Young-suwn Lim, suwnmail@naver.com, (D) https://orcid.org/0000-0002-5218-8768

*Corresponding author: Jaeuk Kim, jaeukkim@kiom.re.kr, (1) https://orcid.org/0000-0003-0408-5569
} 
As a result, the prevalence of chronic degenerative and geriatric diseases is increasing (Kim and Kim, 2007), and various problems of the elderly and people with dementia, a ' $21^{\text {st }}$ century' geriatric disease, are also constantly on the rise. Dementia is a typical geriatric disease that causes continuous damage to intellectual capacity due to disorder in cognitive and language skills such as memory, visuospatial function, and concentration. According to the National Institute of Dementia (2018), there are 705,475 patients expected to have dementia in the elderly population aged 65 and over in Korea, and the prevalence of dementia is $12 \%$.

Recently there is an increasing attention in caring for patients with mild cognitive impairment regarded as potential dementia, as it is a presymptomatic stage of dementia with cognitive decline in progress that is more likely to go on to dementia than normal people. The elderly with subjective memory impairment (SMI) and mild cognitive impairment (MCI) capable of certain daily activities as an intermediate stage of dementia and normal aging are cognitive decline groups that need active care to prevent dementia (Kang et al., 2019). The prevalence of MCI is $24.1 \%$, which is 3 times that of dementia with $8.4 \%$, and approximately $15 \%$ of them go on to dementia (Kang and Baek, 2014), but there are no statistics for the elderly with SMI in which MCI can be predicted.

Previous studies reported positive effects of acupuncture and moxibustion on the elderly with declined cognitive ability on HRV (Kim, 2015), positive changes in depression and emotions of the dementia risk group that participated in therapeutic intervention that combined yoga and breathing compared to the control group (Kim, 2011), positive effects of physical activities on improvement of cerebropathy (Jung, 2008), and positive changes by using art therapy (Kim, 2016), dance therapy (Choi, 2010), rehabilitation (Lee, 2017), plant-based horticultural therapy (Cho, 2014) in preventive and therapeutic intervention.

Risk factors of dementia may include psychological and physical factors (Deckers et al., 2015), and forest therapy programs are effective in reducing anxiety, depression, and stress that are known to be psychological risk factors of dementia (Ochiai et al., 2015). Moreover, heart rate variability (HRV) and steady pulse (Yu et al., 2017), reduction of cortisol level in blood (Park, 2019), positive changes in electroencephalogram (EEG) and heart rate variability (HRV) through forest activities (Kim and Choi, 2019), and positive changes in bioimpedance (Yi et al., 2019) were reported. Based on these results, intervention of forest therapy programs for the elderly at the risk of dementia due to cognitive decline can be an effective approach to prevention of dementia and promotion of psychological and physical health.

Therefore, this study aims to implement a program using the forest environment for the elderly whose cognitive ability is declined or lost in the era of aging and verify the effectiveness of the program by determining the cognitive and physical changes in EEG and HRV as well as psychological effects after the activities.

\section{Research Methods}

\section{Subjects}

This study was conducted for 4 months from August to November 2018 on 60 subjects living in Cheongju, Chungbuk, selected based on the following criteria. The subjects were to be the elderly aged 65 and over with no restrictions on outdoor activities or walking; elderly not taking dementia medication and do not have dementia but are suffering from cognitive decline; elderly that can carry out at least 3 hours of outdoor activities; elderly with no trouble in daily activities and cognitive judgment for the survey or forest activities; and elderly that understood the purpose of this study and submitted the consent for voluntary participation.

\section{Procedures}

The subjects were divided into two groups: 30 subjects in the experimental group hoping to participate in the activity-based programs in a neighborhood urban forest, and 30 subjects in the control group that did not apply any artificial conditions or operations to assess whether the results of the experiment are properly derived.

This study was conducted after obtaining approval (IRB NO, CBNU-201903-BMSB-812-01) based on the deliber- 
ation of the Institutional Review Board (IRB) at Chungbuk National University. The program was carried out from August to November 2018, and we explained the purpose of this study and research process to the relevant centers for dementia and executing welfare agencies and obtained approval for cooperation. To measure the experimental group that participated in the forest therapy program, 3 people that received user training in addition to the researchers measured and analyzed EEG and HRV. The survey was conducted by the cooperation of 2 nurses at the centers for dementia and 2 social workers in charge that received training in advance. The pretest was measured before the program, and the posttest after the program. The program for the experimental group was in total 11 sessions and the pretest and posttest, carried out by 2 forest therapists and 2 assistant instructors every week in a neighborhood urban forest. The control group was measured by the same inspectors in the same method as the experimental group in the pretest and posttest for comparison.

\section{Tools}

This study measured the effects of the program in terms of psychological, cognitive, and physical functions. Since the risk factors of cognitive decline are psychological factors such as depression and stress and physiological factors that deteriorate memory and physical ability, the reliability of results must be increased by the combined analysis of subjective and objective indicators (Lee et al., 2018).

\section{Screening tool: Korean version of the Mini-Mental State Examination (MMSE-DS)}

The MMSE is the Mini-Mental State Examination tool developed by Folstein et al., (1975) and a typical tool that is widely used to screen the damages of cognitive functions simply and quickly (Lee, 2007). The MMSE-DS, which is the Korean version designed based on the MMSE, is a typical dementia screening tool used by the centers for dementia under the community health centers in Korea (Cho, 2018). In this study, it was used as a measurement tool to screen the subjects with cognitive decline, not dementia patients.

\section{Psychological health measurement tool: Korean Form of Geriatric Depression Scale (KGDS)}

This study used the Korean Form of Geriatric Depression Scale (KGDS) to measure psychological depression. The KGDS is a geriatric depression testing tool suitable for the sentiment of Koreans that can effectively distinguish patients with depression. It is a tool with dichotomous scales ("yes"/"no") that can be answered easily by the elderly. It is a useful screening tool for geriatric depression with damaged cognitive functions, and as a self-report questionnaire with total 30 items, higher scores indicate more severe depression (Park, 2008). For diagnosis, the positive and negative items are converted to scores, with 14-18 points classified as borderline mild depression, 19-21 points as moderate depression, and 22 points and higher as severe depression (Kim, 2019).

\section{Cognitive health measurement tool: EEG}

EEG is a noninvasive method that directly shows the functional changes of the cerebrum and has the economic benefit of providing all kinds of useful information in a short time. Thus, measuring EEG is acknowledged as a physiological test that can interpret objective brain functions unlike a self-report assessment. Moreover, EEG can objectively and continuously measure and assess the cerebrum that embrace the mental and physical functions of humans and is thus used in various ways in basic research (Kang et al., 2016). Previous studies on EEG of the elderly comparatively analyzed brain activation of the general elderly and the elderly with dementia after a concentration training program using a computer (Kang et al., 2009), and examined the effects of computer-assisted cognitive rehabilitation training and balance exercises on the elderly's cognition, visual perception, hand functions, balance, and EEG (Lee, 2011).

This study explored the EEG measurement method related to the cognitive process based on literature review and ultimately selected the 2-channel band-type EEG measuring device (neuroNicle FX2, Laxtha, Korea) that can easily measure signals and assess cognitive functions on the frontal lobe of the brain (Choi et al., 2019). The spontaneous resting-state EEG was measured for 5 minutes while 
the subject is sitting in a chair in the eyes-closed resting state without dozing off. The measured EEG signals are used in analyzing peak frequency, which is the peak of the intrinsic rhythm in the resting state through the quantitative EEG (qEEG) analysis.

\section{Physical health measurement tool: heart rate variability (HRV)}

Noninvasive HRV (photoplethysmogram, PPG) measurement has been used to assess autonomic nerve reactions or vascular load and vascular aging. In particular, to check the autonomic nerve reactions, Fourier transform is applied to the slight variance of the heartbeat (HRV) at the HRV signal, and the power spectrum is divided into frequency sections, with high frequency component $(\mathrm{HF}, 0.15 \mathrm{~Hz}-0.4 \mathrm{~Hz})$ representing parasympathetic nerve activity, low frequency component (LF, $0.04 \mathrm{~Hz}-0.15 \mathrm{~Hz})$ representing sympathetic nerve and parasympathetic nerve activity, and the ratio variable $\mathrm{LF} /(\mathrm{HF}+\mathrm{LF})$ representing relative sympathetic nerve activity. Stress levels according to autonomic nerve reactions can be determined by HRV analysis, thereby quantifying the physical and mental stress levels of the elderly population. PPG was measured using the tweezer-type device clipped onto a finger (ubpulse T1, Laxtha, Korea). The PPG waves on the left-hand forefinger were measured for 5 minutes with the subject sitting in a chair in a resting state. This study used HF that represents parasympathetic nerve activity in the analysis to examine the relaxation effect of forest therapy activities.

\section{Composition and contents of the forest therapy program}

The program was developed using forest therapy elements that help prevent cognitive decline of the elderly, and the contents are based on walking and exercising using the forest environment and forest therapy factors of the research site. More specifically, the program included clapping with fingers/back of the hands/palms to help prevent cognitive decline, band exercises to increase flexibility of the body and strengthen the muscles, and walking in the forest with adzuki beans fixed to the deepest depression of the sole when the toes are flexed so that the sole can be stimulated by acupressure while walking (Kim and Koo, 2019). Moreover, walking encouraged the elderly living alone $(49 \%)$ to promote a sense of social belonging and relieve depression by having conversations and getting acquainted with one another (Lee et al., 2018). The intensity of walking was to the level of light perspiration to induce physical health and relax autonomic nerves (Xing, 2019). There were total 11 sessions of the program as summarized in Table 1. The program was carried out once a week from 10:00 a.m. to 12:00 p.m. and at the same time in each session, the subjects learned the cardio exercises and muscle-strengthening exercises, gradually increasing the intensity in the initial rating of perceived exertion from 14 (intensity 1-3) to 16-17 (intensity 7-9).

\section{Data analysis}

Data collected from the experimental group and control group were analyzed using the SPSS Version 21.0 Program. General characteristics were analyzed with frequency analysis of descriptive statistics, and cross-tabulations are used to test the homogeneity between the groups. In addition, a paired t-test was conducted to determine whether there is statistical significance in the (pretest and posttest) results before and after 11 sessions of the forest therapy program, and the significance level was $p<.05$ (Kang et al., 2020). From the data measured and not omitted from the pretest and posttest, the cases in which there were errors in the extraction of variables due to intake of psychoactive or cardiovascular drugs were excluded. As a result, as shown in Fig. 1, 25 subjects in the control group and 30 in the experimental group were used in the analysis for KGDS; 20 in the control group and 27 in the experimental group for EEG; and 21 in the control group and 29 in the experimental group for HRV.

\section{Results and Discussion}

\section{General characteristics of the groups and homogeneity test results}

The general characteristics of the subjects are presented 
Table 1. Contents of forest healing program for dementia prevention

\begin{tabular}{|c|c|c|}
\hline & Program contents & Effect \\
\hline $\begin{array}{l}\text { Baseline } \\
\text { mesurement }\end{array}$ & $\begin{array}{l}\text { EEG Test, HRV test, } \\
\text { Demographic questionnaire GDS-K, MMSE }\end{array}$ & Effect measurement \\
\hline $1^{\text {st }}$ session & $\begin{array}{l}\text { Orientation, Ice breaking } \\
\text { Forest walking (Yongcheon stimulation:200m) } \\
\text { Band gymnastics (strength 1 3) }\end{array}$ & $\begin{array}{l}\text { Reduce the tension } \\
\text { Promote health and reduce depression } \\
\text { Stretching, strength, body flexibility }\end{array}$ \\
\hline $2^{\text {nd }}$ session & $\begin{array}{l}\text { Cognitive enhancing clap (Health clap) } \\
\text { Forest walking (Yongcheon stimulation:500m) } \\
\text { Band gymnastics (strength } 1 \sim 3 \text { ) }\end{array}$ & $\begin{array}{l}\text { Circulatory and cognitive function of the body } \\
\text { Promote health and reduce depression } \\
\text { Stretching, strength, body flexibility }\end{array}$ \\
\hline $3^{\text {rd }}$ session & $\begin{array}{l}\text { Cognitive enhancing clap (Health clap) } \\
\text { Forest walking (Yongcheon stimulation:500m) } \\
\text { Band gymnastics (strength } 1 \sim 3 \text { ) }\end{array}$ & $\begin{array}{l}\text { Circulatory and cognitive function of the body } \\
\text { Promote health and reduce depression } \\
\text { Stretching, strength, body flexibility }\end{array}$ \\
\hline $4^{\text {th }}$ session & $\begin{array}{l}\text { Cognitive enhancing clap (Health clap) } \\
\text { Forest walking (Yongcheon stimulation:500m) } \\
\text { Band gymnastics (strength } 4 \sim 6 \text { ) }\end{array}$ & $\begin{array}{l}\text { Circulatory and cognitive function of the body } \\
\text { Promote health and reduce depression } \\
\text { Stretching, strength, body flexibility }\end{array}$ \\
\hline $5^{\text {th }}$ session & $\begin{array}{l}\text { Cognitive enhancing clap (337 clap) } \\
\text { Forest walking (Yongcheon stimulation:700m) } \\
\text { Band gymnastics (strength } 4 \sim 6 \text { ) }\end{array}$ & $\begin{array}{l}\text { Circulatory and cognitive function of the body } \\
\text { Promote health and reduce depression } \\
\text { Stretching, strength, body flexibility }\end{array}$ \\
\hline $6^{\text {th }}$ session & $\begin{array}{l}\text { Cognitive enhancing clap ( } 337 \text { clap) } \\
\text { Forest walking (Yongcheon stimulation:700m) } \\
\text { Band gymnastics (strength } 4 \sim 6 \text { ) }\end{array}$ & $\begin{array}{l}\text { Circulatory and cognitive function of the body } \\
\text { Promote health and reduce depression } \\
\text { Stretching, strength, body flexibility }\end{array}$ \\
\hline $7^{\text {th }}$ session & $\begin{array}{l}\text { Cognitive enhancing clap (337 clap) } \\
\text { Forest walking (Yongcheon stimulation:700m) } \\
\text { Band gymnastics (strength 7 9) }\end{array}$ & $\begin{array}{l}\text { Circulatory and cognitive function of the body } \\
\text { Promote health and reduce depression } \\
\text { Stretching, strength, body flexibility }\end{array}$ \\
\hline $8^{\text {th }}$ session & $\begin{array}{l}\text { Rhythmic gymnastics } \\
\text { Forest walking (Yongcheon stimulation:1000m) } \\
\text { Band gymnastics (strength 7 9) }\end{array}$ & $\begin{array}{l}\text { Circulatory and cognitive function of the body } \\
\text { Promote health and reduce depression } \\
\text { Stretching, strength, body flexibility }\end{array}$ \\
\hline $9^{\text {th }}$ session & $\begin{array}{l}\text { Rhythmic gymnastics } \\
\text { Forest walking (Yongcheon stimulation:1000m) } \\
\text { Band gymnastics (strength 7 9) }\end{array}$ & $\begin{array}{l}\text { Circulatory and cognitive function of the body } \\
\text { Promote health and reduce depression } \\
\text { Stretching, strength, body flexibility }\end{array}$ \\
\hline $10^{\text {th }}$ session & $\begin{array}{l}\text { Rhythmic gymnastics } \\
\text { Forest walking (Yongcheon stimulation:1000m) } \\
\text { Band gymnastics (strength 7 9) }\end{array}$ & $\begin{array}{l}\text { Circulatory and cognitive function of the body } \\
\text { Promote health and reduce depression } \\
\text { Stretching, strength, body flexibility }\end{array}$ \\
\hline $11^{\text {th }}$ session & $\begin{array}{l}\text { Rhythmic gymnastics } \\
\text { Forest walking (Yongcheon stimulation:1000m) } \\
\text { Band gymnastics (strength 7 9) }\end{array}$ & $\begin{array}{l}\text { Circulatory and cognitive function of the body } \\
\text { Promote health and reduce depression } \\
\text { Stretching, strength, body flexibility }\end{array}$ \\
\hline $\begin{array}{c}\text { Post } \\
\text { measurement }\end{array}$ & $\begin{array}{l}\text { EEG Test, HRV test, } \\
\text { demographic questionnaire GDS-K }\end{array}$ & $\begin{array}{l}\text { EEG Test, HRV test, demographic questionnaire } \\
\text { GDS-K }\end{array}$ \\
\hline
\end{tabular}

in Table 2 based on frequency analysis of descriptive statistics. The average age of the control group was 74.7, the religion with highest frequency was Christianity followed by Buddhism, and 53.3\% were living with their spouses and $40.0 \%$ were bereaved. At least $90 \%$ neither drank nor smoked, 6.7\% had experience participating in a related program, and $86.7 \%$ responded that they are willing to participate again. The average age of the experimental group was 73.6, the religion with highest frequency was no religion followed by Christianity and Christianity, and $51.6 \%$ were living with their spouses and $45.2 \%$ were bereaved. At least 90\% neither drank nor smoked, 42\% had experience participating in a related program, and $100 \%$ responded that they are willing to participate again. Table 3 shows the result of testing homogeneity between the groups through an independent samples t-test. There 


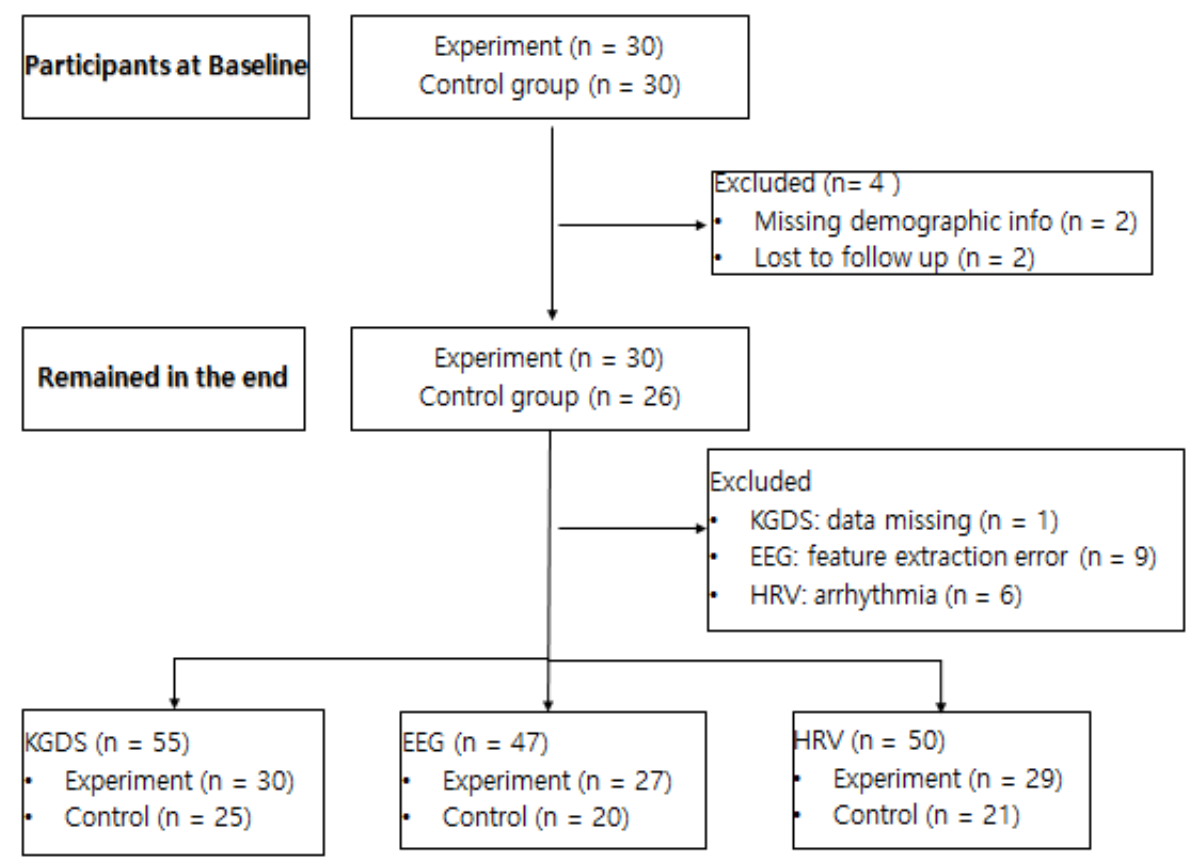

Fig. 1. Number of participants for the analysis according to the study flow.

Table 2. Results of demographic information

\begin{tabular}{|c|c|c|c|c|c|c|}
\hline \multirow{2}{*}{ Item } & \multicolumn{3}{|c|}{ Control group } & \multicolumn{3}{|c|}{ Experiment group } \\
\hline & Item & Frequency & Ratio(\%) & Item & Frequency & Ratio(\%) \\
\hline \multirow{5}{*}{ Religion } & Budism & 11 & 36.7 & Budism & 7 & 23.3 \\
\hline & Catholic & 1 & 3.3 & Catholic & 3 & 10.0 \\
\hline & Christian & 12 & 40.0 & Christian & 9 & 30.0 \\
\hline & None & 6 & 20.0 & None & 11 & 36.7 \\
\hline & Total & 30 & 100 & Total & 30 & 100 \\
\hline \multirow{5}{*}{$\begin{array}{l}\text { Merrital } \\
\text { state }\end{array}$} & Merried & 16 & 53.3 & Merried & 16 & 53.3 \\
\hline & Single & 1 & 3.3 & Single & 1 & 3.4 \\
\hline & Bereavement & 12 & 40.0 & Bereavement & 13 & 43.3 \\
\hline & Divorce & 1 & 3.4 & Divorce & 0 & 0 \\
\hline & Total & 30 & 100 & Total & 30 & 100 \\
\hline \multirow{3}{*}{ Smoking } & Yes & 1 & 3.4 & Yes & 1 & 3.4 \\
\hline & No & 29 & 96.6 & No & 29 & 96.6 \\
\hline & Total & 30 & 100 & Total & 30 & 100 \\
\hline \multirow{3}{*}{ Alcohol } & Yes & 1 & 3.4 & Yes & 2 & 3.7 \\
\hline & No & 29 & 96.6 & No & 28 & 93.3 \\
\hline & Total & 30 & 100 & Total & 30 & 100 \\
\hline \multirow{3}{*}{$\begin{array}{c}\text { Dementia } \\
\text { program } \\
\text { experience? }\end{array}$} & Yes & 2 & 6.7 & Yes & 1 & 3.4 \\
\hline & No & 28 & 93.3 & No & 29 & 96.6 \\
\hline & Total & 30 & 100 & Total & 30 & 100 \\
\hline \multirow{3}{*}{$\begin{array}{l}\text { Willingness to } \\
\text { attend again }\end{array}$} & Yes & 26 & 86.7 & Yes & 30 & 100 \\
\hline & No & 4 & 13.3 & No & 0 & 0 \\
\hline & Total & 30 & 100 & Total & 29 & 100 \\
\hline
\end{tabular}


Table 3. Independent sample t-test for analyzing homogeneity between experiment and control groups

\begin{tabular}{|c|c|c|c|c|c|c|c|c|}
\hline \multirow{2}{*}{ Item } & \multicolumn{3}{|c|}{ Control group } & \multicolumn{3}{|c|}{ Experiment group } & \multirow{2}{*}{$\mathrm{t}$} & \multirow{2}{*}{$p$} \\
\hline & $\mathrm{n}$ & Mean & SD & $\mathrm{n}$ & Mean & SD & & \\
\hline MMSE & 24 & 25.582 & 3.189 & 29 & 25.934 & 4.242 & -.331 & .742 \\
\hline KGDS & 25 & 8.4000 & 6.714 & 30 & 11.800 & 6.277 & -1.94 & .058 \\
\hline EEG & 20 & 9.214 & .769 & 27 & 9.182 & .676 & 0.151 & .881 \\
\hline HRV & 21 & 4.034 & .956 & 29 & 4.585 & 1.149 & -1.79 & .079 \\
\hline
\end{tabular}

Table 4. Changes in depression scale (KGDS) by paired sample t-test

\begin{tabular}{lccccc}
\hline & Mean & $\mathrm{n}$ & SD & T & $p$ \\
\hline Control_KGDS_before & 8.400 & 25 & 6.714 & -0.647 \\
Control_KGDS_after & 7.600 & 25 & 5.979 & .523 \\
Forest_Healing_KGDS_before & 11.800 & 30 & 6.277 & 5.355 & -4.503 \\
Forest_Healing_KGDS_after & 8.533 & 30 & & $<.001$ \\
\hline
\end{tabular}

Table 5. Changes in EEG peak frequency by paired samples T-Test

\begin{tabular}{|c|c|c|c|c|c|}
\hline & Mean & $\mathrm{n}$ & SD & $\mathrm{T}$ & $p$ \\
\hline Control_EEG_before & 9.213 & 20 & .769 & \multirow{2}{*}{-1.016} & \multirow{2}{*}{.322} \\
\hline Control_EEG_after & 9.129 & 20 & .927 & & \\
\hline Forest_healing_EEG_before & 9.182 & 27 & .679 & \multirow{2}{*}{2.539} & \multirow{2}{*}{.017} \\
\hline Forest_healing_EEG_after & 9.409 & 27 & .825 & & \\
\hline
\end{tabular}

was a difference in each mean, but the $\mathrm{P}$ values were $\operatorname{MMSE}(p=.742), \operatorname{KGDS}(p=.058), \operatorname{EEG}(p=.881)$, and HRV $(p=.079)$, showing no statistically significant difference between the two groups. In other words, each measurement variable turned out to be the same.

\section{Results of pretest-posttest KGDS depending on the implementation of the forest therapy program}

To assess the effects of the forest therapy program on depression, we conducted a t-test on the pretest-posttest score differences in each group. As shown in Table 4, the depression level in the experimental group decreased by 3.267 on average, showing a statistically significant change $(p<.001)$. However, in the control group, the depression level decreased by around 0.800 on average, but it was not statistically significant $(p=.523)$. This effect may be due to the walking exercises in the forest in which the subjects can continuously contact the forest, participation of multiple people in the forest, and the environmental pos- sibilities of the forest. Depression may have been relieved through the forest therapy elements that induce pleasant emotions in the forest that is more open and free than indoors, regular physical activities, and a bond shared by the participants with similar conditions and identity to promote health, thereby relieving social isolation and loneliness. This result is consistent with previous studies reporting the effect of forest therapy programs on promoting emotional stability and relieving general stress (Ochiai et al., 2015; Yu et al., 2017).

\section{Results of EEG analysis depending on the implementation of the forest therapy program}

As shown in Table 5, for the effects of the forest therapy program measured with EEG, eigenfrequency of the experimental group showed a statistically significant increase after participating in the program. Peak frequency $(\mathrm{PF})$ in the experimental group increased by 0.227 on average after the program, showing a statistically significant change 
( $p=.017$ ). However, in the control group, the PF change during the same period was not significant $(p=.322)$, which is consistent with the previous study that cognitive decline in the elderly population lowers the peak frequency (Choi et al, 2019). By sticking adzuki beans on the deepest depression of the sole when the toes are flexed and having the subjects walk until they sweat lightly, and by making them experience the topographic changes of the forest and active physical activities that simulate the spots on the body suitable for acupuncture by clapping (So, 2013), there was a positive effect on inducement of cognitive stimulation and promotion of remaining cognitive capacity of the subjects. This is in line with the studies reporting that exposure to the forest and appropriate exercise have positive effects on increase of $\alpha$-waves of EEG, psychological stability, and improvement of physical functions (Choi, 2012; Lee et al., 2014; Park et al., 2018).

\section{Results of HRV analysis depending on the implementation of the forest therapy program}

Changes in HRV after the forest therapy program are as shown in Table 6. The HF of HRV that responds to stress and measures adaptability of the autonomous nervous system increased by 0.396 on average in the experimental group after the program, showing a statistically significant change ( $p=.035)$ and thereby activating parasympathetic nerves and inducing physical relaxation. However, the control group showed an increase of 0.274 , which was not statistically significant. This is consistent with the results of previous studies that regular exposure to the forest environment and natural physical activities such as taking walks and breathing brought psychological stability and relaxation to the subjects, regular and continuous physical activities enough to sweat lightly increase activity of the parasympathetic nervous system (Lee et al., 2012), and forest therapy programs in the forest have significant effects on physical relaxation and fatigue (Park et al., 2014; Park et al., 2015).

\section{Conclusion}

This study was conducted to determine the effects of forest therapy programs, intended to prevent dementia of the elderly aged 65 and over with cognitive decline, on cognitive, psychological, and physical health. The subjects were the elderly aged 65 and over with cognitive decline living in urban areas that are not registered as dementia on the National Health Insurance Service. The following conclusions can be drawn from the results of this study. The depression scale of the subjects, which can be a presymptom of dementia, showed significant results in the experimental group that experienced the program, which implies that forest-based therapy programs are significant for participants that are intimidated by their psychological experience of stress and severance of relations in senescence. A significant increase was observed in the alpha peak frequency of resting-state EEG that reflects the state of cognitive decline. This effect implies that various activities in the forest prevent aging of the brains. Also in the autonomic nerve reactions index, forest therapy activities increased the HF, which is the index of parasympathetic nerve activity, inducing psychological stability and physical relaxation for improvement.

In sum, as a result of comparing the control group with the experimental group that participated in the forest therapy program, the experimental group that carried out forest therapy activities in the forest during the same period of time generally showed improvement and positive effects in psychological, cerebral and neurological, and autonomic

Table 6. Changes in HF in heart rate variability by paired samples t-test

\begin{tabular}{llllll}
\hline & Mean & $\mathrm{n}$ & SD & T & $p$ \\
\hline Control_HRV_before & 4.034 & 21 & .956 & 1.141 \\
Control_HRV_after & 4.309 & 21 & 1.182 & 1.149 & .267 \\
Forest_healing_HRV_before & 4.585 & 29 & 29 & 1.137 & 2.217 \\
Forest_healing_HRV_after & 4.981 & & .035 \\
\hline
\end{tabular}


nervous indexes. Outbreak of dementia is an urgent problem at this point in which the population is rapidly aging, and early detection and initial intervention are important in order to delay the progress of the disease and reduce socioeconomic costs. To this end, forest therapy programs with proven effects for the elderly with cognitive decline can be used. In particular, by applying programs with forest therapy elements in urban parks and neighborhood forests for the elderly that cannot go to a forest far away due to lack of physical freedom, it will be possible to help prevent cognitive decline and promote health of the elderly.

Based on these results, we intend to make the following suggestions. First, we suggest an environment with expanded forests and natural elements in the suburbs for the elderly without much freedom of activity even though they are continuously increasing, so that the alienated elderly can be healthy in both mind and body by having access to nature. Second, $60 \%$ of the hobbies in Korea are statistically comprised of mountain climbers. This may be not only due to the environmental nature of Korea in which $64 \%$ of the national territory are mountains, but also because Koreans have a primary instinct regarding forests. Even though various programs are actively implemented in each local government or the Ministry of Health and Welfare and centers for dementia under the national responsibility policy for dementia care, but there are not many official forest therapy programs. Therefore, institutionally developing and applying programs for the elderly with progressive cognitive decline will help improve the quality of life and reduce medical expenses by preventing cognitive decline.

\section{References}

Cho, J.H. 2014. A comparison of cognitive impairment level according to characteristics and MMSE-DS of the elderly. Master's thesis, Korea National Open University, Seoul, Korea.

Cho, M.H. 2018. The effect of an individual cognitive improvement program in home visiting health service. Master's thesis, Hanyang University, Seoul, Korea.

Choi, J.M., B.C. Ku, Y.G You, M.J. Jo, M.J. Kwon, Y.Y.
Choi, S.Y. Jung, S.Y. Ryu, E.J. Park, H.Y. Go, G.H. Kim, W.S. Cha, and J.U. Kim. 2019. Resting-state prefrontal EEG biomarkers in correlation with MMSE scores in elderly individuals. Sci. Rep. 9(1):10468. https://doi.org/10.1038/s41598-019-46789-2

Choi, S.W. 2012. The effect of 24 weeks of exercise program on cognitive function and health-related physical fitness in elderly persons with mild dementia. Korean J. Sports Sci. 21(6):1087-1098.

Choi, Y.J. 2010. The effects of dance therapy by rhythm exercise on the cognitive function memory performance and depression of the aged female's with dementia. Doctoral dissertation, Kangwon National University, Seoul, Korea.

Deckers, K., M.P. van Boxtel, O.J. Schiepers, M. de Vugt, J.L. Muñoz Sánchez, K.J. Anstey, C. Brayne, J.F. Dartigues, K. Engedal, M. Kivipelto, K. Ritchie, J.M. Star, K. Yafe, K. Irving, F.R. Verhey, and S. Köhler. 2015. Target risk factors for dementia prevention: a systematic review and delphi consensus study on the evidence from observational studies. Int. J. Geriatr. Psychiatry. 30(3):234-246. https://doi.org/10.1002/gps.4245

Folstein, M.F., S.E Folstein, and P.R. Mchugh. 1975. "Mini-mental state" a practical method for grading the cognitive state of patients for the clinician. J. Psychiat Res. 12:189-198.

Jung, H.I. 2008. A review of literature on effects of regular exercise on physical cognive functions among demented Elders. Master's thesis, SungShin University, Seoul, Korea.

Kang, B.H. and W.S. Shin. 2020. Forest therapy program reduces academic and job-seeking stress among college students. J. People Plants Environ. 23(3): 363-375. https://doi.org/10.11628/ksppe.2020.23.3.363

Kang, B.W., M.H. Jung, and B.J. Cho. 2016. The effects of psychological factors on elderly of depression scale and electroephalography. J. Korea Soc. Comput. Inf. 21(12):157-163. https://doi.org/10.9708/jksci.2016.21.1 2.157

Kang, M.A. and Y.M. Baek. 2014. The neurocognitive function between the patients who had subjective memory impairment and mild cognitive impairment. J. Korean Geriatr. Soc. 18(1):7-15. https://doi.org/10.4235/jkgs.20 14.18.1.7

Kang, S.J., S.H. Park, and J.W. Kim. 2019. The character- 
istics of semantic association task performance in elderly with subjective memory impairment and mild cognitive impairment. J. Digit. Converg. 17(2):283-292. https://doi.org/10.14400/JDC.2019.17.2.283

Kang, W.K., M.H. Kang, J.L. Yang, E.J. Ku, and S.K. Kim. 2009. The comparison of EEG activity by computer assisted cognitive rehabilitation program in the normal elderly and the elderly with dementia. J. Korean Soc. Occupational Therapy. 17(3):1-13.

Kim, H.J. 2011. Effects of yoga therapy program on cognitive function, depression and self-esteem focusing on high risk group of dementia. Doctoral dissertation, Seoul University of Buddhism, Seoul, Korea.

Kim, H.S. and B.S. Kim. 2007. The effect of self-esteem on the relationship between the elderly stress and depression. J. Korean Gerontol. Soc. 27(1):23 37.

Kim, H.S. 2016. The effects of reminiscence-centered integrative arts therapy on cognitive function, life satisfaction, depression, anxiety of elderly with dementia. Master's thesis, Kyunggi University, Seoul, Korea.

Kim, K.Y. 2019. A Study on Elderly People's Response Characteristics on Draw-A-Story (DAS) Acoording to their Depression levels. Master's thesis, Ewha Women University, Seoul, Korea.

Kim, I.D. and C.D. Koo. 2019. A study of walking, viewing and fragrance-based forest therapy programs effect on living alone adults' dementia prevention. Korean J. Environ. Ecol. 33(1):107-115. https://doi.org/10.13047/KJEE.201 9.33.1.107

Kim, J,K. and K.H. Choi. 2019. The effect of forest experience program on brain waves \& pulse waves. J. Korea Entertain. Ind. Assoc. 13(4):185-194. doi:10.21184/jkei a.2019.6.13.4.185.

Kim, W.K. 2015. A study on measurement technique of HRV for elder with reduced cognitive abilities. J. Korea. Inst. Electronic Telecommun Sci. 10(1):125-132.

KOSIS (Korean Statistical information service). 2018. Future population estimation. Retrieved from http://www.kosis. kr. https://www.nid.or.kr/info/dataroom_view.aspx?bid $=183$

Lee, B.K. and H.H. Lee. 2012. A study on the effects of human physiology after forest phytoncide therapy. J. Naturopathy. 1(1):14-20.
Lee, H.J. and S.A. Son. 2018. Qualitative assessment of experience on urban forest therapy program for preventing dementia of the elderly living alone in low-income class. J. People Plants Environ. 21(6):565-574. https://doi.org/ 10.11628/ksppe.2018.21.6.565

Lee, J.S. 2017. The effects of cognitive rehabilitation on the activities of daily living and cognitive function with dementia in silver care centers. Master's thesis, Korea University, Seoul, Korea.

Lee, S.S. 2007. Review study of clinical availability for screening test (MMSE, GDS, CDR). Master's thesis, Hanyang University, Seoul, Korea.

Lee, Y.H., C.W Park, and J.J. Kim. 2014. Effects of visual stimulus with forest scenery types on psychological and physiological status of humanity. J. Korean Soc. People Plants Environ. 17(1):65-71. https://doi.org/10.11628/ks ppe.2014.17.1.065

Lee, Y.M. 2011. Cognitive rehabilitation training and balance exercise on cognition, visual perception, hand function, balance and electroencephalography in the elderly. Doctoral dissertation, Daegu University, Daegu, Korea.

National Instiute of Dementia. 2018. Free country from dementia (Report No. NIDR 1802-0023). Seongnam, Korea. retrieved form http://www.nid.or.kr.

Ochiai, H., H. Ikei, C. Song, M. Kobayashi, T. Miura, T. Kagawa, Q. Li, S. Kumeda, M. Imai, and Y. Miyazaki. 2015. Physiological and psychological effects of a forest therapy program on middle-aged females. Int. J. Environ. Res. Public Health 12(12):15222-15232. https://doi.org/ 10.3390/ijerph121214984.

Park, C.E. 2019. Effects of forest stress management program on middle aged women's physio-psychological improvement. Doctoral dissertation, Chungbuk National University, Cheongju, Korea.

Park, H.S., C.S, Shin, P.S, Yeoun and J.Y. Kim. 2014. A comparative study on the stress recovery effect of forest therapy. J. Korean Inst. For. Recreat. 18(1):13-24. https://doi.org/10.34272/forest.2014.18.1.002

Park, J.Y. 2008. Development and effect of ceramic activities program on ederly depression and life satisfaction. Master's thesis, Catholic University of Daegu, Daegu, Korea.

Park, S.A., M.S. Jung, and M.W. Lee. 2015. An analysis of the healing effects of forest therapy and horticultural 
therapy. J. Korean Inst. Landsc. Archit. 43(3):43-51. https://doi.org/10.9715/KILA.2015.43.3.043

Park, S.K. and B.K. Kim. 2018. The effects forest exercise on brain wave for lifetime health management. J. Korea Entertain. Ind. Assoc. 12(2):99-106. https://doi.org/10.2 1184/jkeia.2018.2.12.2.99

So, S.M. 2013. Effects of healthy clapping program on stress and depression tendency. Master's thesis, Chungnam National University, Daejeon, Korea.

Xing, L. 2019. Effects of forest walking exercise on brain and physical health and stress in middle-aged females. Doctoral dissertation, Hallym University, Chuncheon, Korea.
Yi, J.Y., B.C. Ku, S.G. Kim, T.G, Khil, Y.S, Lim, M.J, Shin, S.J, Jeon, J.G, Kim, B.H, kang, J.Y, Shin, K.H, Kim, A.Y, Jeong, J.H, Park, J.M, Choi, W.S, Cha, C.S, Shin, W.S, Shin and J.U, Kim. 2019. Traditional Korean medicinebased forest therapy programs providing electrophysiological benefits for elderly individuals. Int. J. Environ. Res. Public Health. 16(22):4325-4345. https://doi.org/10.339 0/ijerph16224325

Yu, C.P., C.M. Lin, M.J. Tsai, Y.C. Tsai, and C.Y. Chen. 2017. Effects of short forest bathing program on autonomic nervous system activity and mood states in middleaged and elderly individuals. Int. J. Environ. Res. Public Health. 14(8):897-909. https://doi.org/10.3390/ijerph140 80897 